\title{
Nitrogen-doped carbons in Li-S batteries: materials design and electrochemical mechanism
}

\author{
Xia Li and Xueliang Sun* \\ Department of Mechanical and Materials Engineering, University of Western Ontario, London, ON, Canada
}

\section{Edited by:}

Hua Kun Liu, University of

Wollongong, Australia

\section{Reviewed by:}

Manickam Minakshi, Murdoch

University, Australia

Babak Shalchi Amirkhiz, Natural

Resources Canada, Canada

Jiulin Wang, Shanghai Jiao Tong

University, China

*Correspondence:

Xueliang Sun, Department of Mechanical and Materials

Engineering, University of Western

Ontario, Spencer Engineering

Building, London, ON N6A 5B9,

Canada

e-mail:xsun@eng.uwo.ca
Li-S batteries have been considered as next generation Li batteries because of their hightheoretical energy density. Over the past few years, researchers have made significant efforts in breaking through critical bottlenecks, which impede the commercialization of Li-S batteries. Beginning with a basic introduction to Li-S systems and their associated mechanism, this review will highlight the application of one specific carbon family, nitrogen-doped carbon materials in sulfur-based cathodes. These materials will include nitrogen-doped porous carbon, carbon nanotubes, nanofibers, and graphene. The article will conclude with a summary of recent research efforts in this field as well as the future prospects for the use of nitrogen-doped carbon materials in Li-S batteries.

\section{Keywords: nitrogen-doped carbon materials, Li-S batteries, sulfur cathodes, lithium sulfide cathodes, heteroatom} effect

\section{INTRODUCTION}

The exponential consumption of fossil fuels has driven a large exploratory effort in the search for sustainable renewable energy sources and energy storage systems. Batteries as a powerful successor have taken a dominant role for the application of large electrical devices (Dunn et al., 2011; Goodenough and Kim, 2011). Since the introduction of Li-ion batteries (LIBs) by Sony in the early 1990s, these energy storage devices have been received extensive attention for the use in everyday-life portable devices, electrical grid, military, and electric vehicles (EVs) (Armstrong et al., 2013; Lee et al., 2013). Compared with other kinds of batteries, LIBs are competitive candidates owing to their high-energy density and long-cycle life (Rousse and Tarascon, 2014; Xu et al., 2014). However, the energy output of current commercialized LIBs still cannot meet the requirements for the development of EVs and hybrid electric vehicles (HEVs) with long-driving range (Gao and Yang, 2010). Owing to this inadequacy, the exploration of high-energy batteries is still critical for the development and application of Li-based batteries. $\mathrm{Li}-\mathrm{S}$ and $\mathrm{Li}$-air batteries are considered as next generation energy storage devices with superiorly high-theoretical capacity and energy density, and are well suitable for the use in EVs and HEVs (Song et al., 2013; Wang et al., 2013a; Zhang, 2013). In this review, a brief introduction of Li$S$ batteries with their advantages, challenges, and opportunities will be discussed. Following this, elaborations on the application of nitrogen-doped carbon materials, one specific family in $\mathrm{Li}-\mathrm{S}$ systems, will be given.

\section{MECHANISM AND CHALLENGES OF Li-S BATTERIES}

The configuration of Li-S batteries is similar to LIBs, which is composed of sulfur-based cathode, Li metal anode, and electrolyte in the middle to separate the two electrodes, as shown in Figure 1. The electrochemical reaction mechanism of $\mathrm{Li}-\mathrm{S}$ batteries, however, is different from LIBs. Charging and discharging in layer-structured cathode and anode materials for LIBs are typically governed by a simple intercalation/deintercalation process (Evers and Nazar, 2013; Manthiram et al., 2013; Yin et al., 2013). Unlike LIBs, cathode materials for Li-S systems are composed of $S_{x}$ molecules embedded within a host material, such as carbon, while the anode employs Li foil (Bruce et al., 2012; Song et al., 2013). During a typical discharge process, the $S_{8}$ ring is broken and forms an extended polysulfide chain. The long-chain polysulfides are then subsequently reduced down to shorter chain polysulfides, until their final form of either $\mathrm{Li}_{2} \mathrm{~S}_{2}$ or $\mathrm{Li}_{2} \mathrm{~S}$ is obtained. This process is then reversed during the charge step. The overall electrochemical reactions have been proposed to occur in following manner (Wang et al., 2013; Yin et al., 2013; Zhang, 2013):

$$
\begin{aligned}
& 2 \mathrm{Li}^{+}+\mathrm{S}_{8}^{2-} \Leftrightarrow \mathrm{Li}_{2} \mathrm{~S}_{8} \\
& 2 \mathrm{Li}^{+}+\mathrm{S}_{4}^{2-} \Leftrightarrow \mathrm{Li}_{2} \mathrm{~S}_{4} \\
& 2 \mathrm{Li}^{+}+\mathrm{S}_{2}^{2-} \Leftrightarrow \mathrm{Li}_{2} \mathrm{~S}_{2} \\
& 2 \mathrm{Li}^{+}+\mathrm{S}^{2-} \Leftrightarrow \mathrm{Li}_{2} \mathrm{~S}
\end{aligned}
$$

The most appealing advantage of sulfur cathodes in Li-batteries is the ultra-high-theoretical energy density $\left(\sim 2600 \mathrm{Wh} \mathrm{kg}^{-1}\right)$. Compared to the lithium metal oxide cathode materials typically used in LIBs, elemental sulfur has a much lower molar weight while also being able to undergo multi-electron reactions with Li metal. These advantages allow sulfur cathode materials to have an ultrahigh theoretical specific capacity, nearly 10 


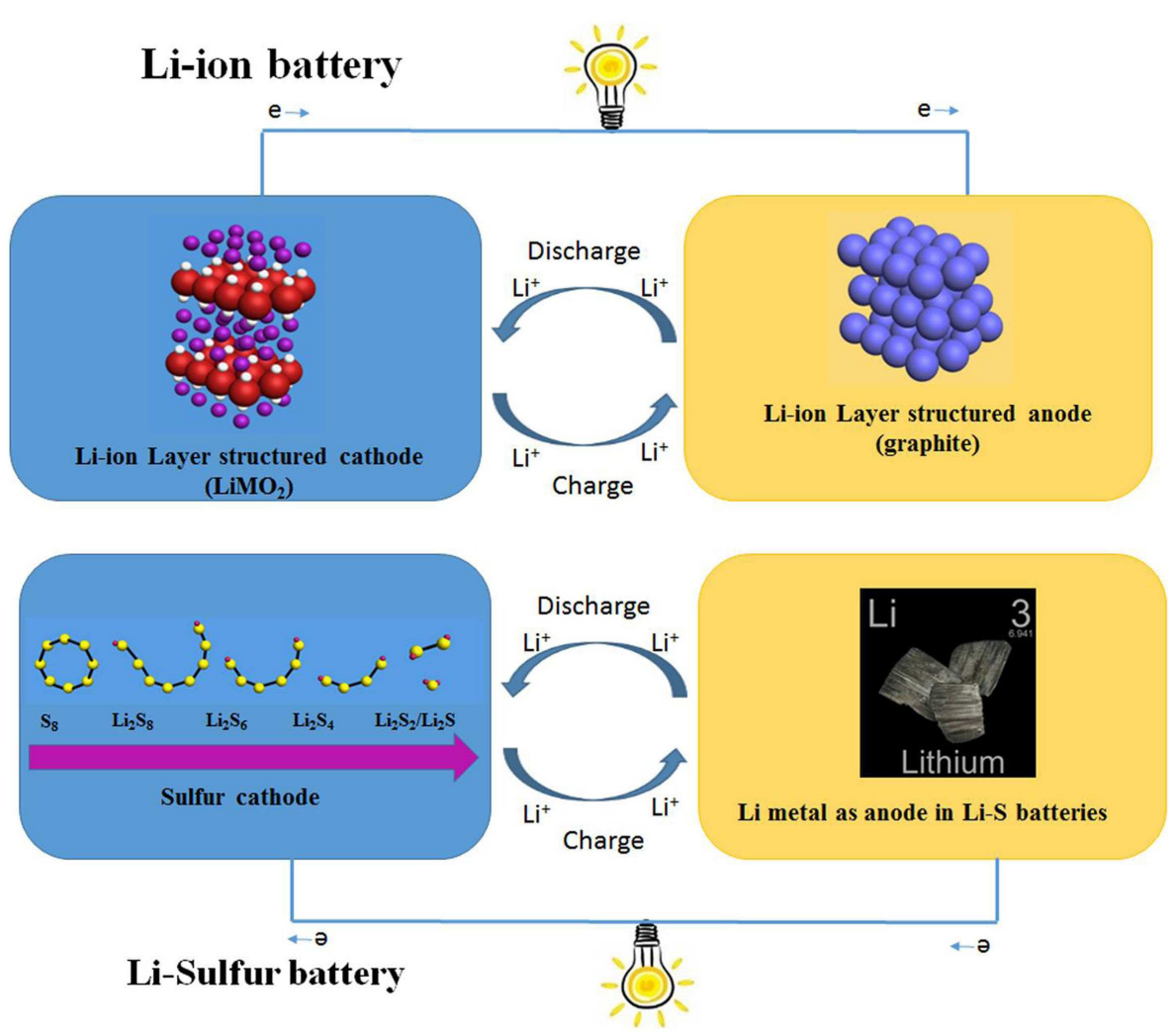

FIGURE 1 | Configuration of Li-ion and Li-S batteries in terms of cathode and anode materials

Table 1 |Theoretical capacity, energy density, and working voltage of cathode materials

\begin{tabular}{|c|c|c|c|}
\hline $\begin{array}{l}\text { Cathode } \\
\text { material }\end{array}$ & $\begin{array}{l}\text { Working } \\
\text { voltage (V) }\end{array}$ & $\begin{array}{l}\text { Theoretical capacity } \\
\qquad\left(\mathrm{mA} \mathrm{h}^{-1}\right)\end{array}$ & $\begin{array}{l}\text { Energy density } \\
\left(\mathbf{W h ~ k g}^{-1}\right)\end{array}$ \\
\hline Sulfur & 2.2 & 1675 & 2566 \\
\hline $\mathrm{Li}-\mathrm{O}_{2}$ & 3.0 & 3840 & 3505 \\
\hline Li-ion & $3.0-5.0$ & $100-270$ & $400-700$ \\
\hline
\end{tabular}

times greater than current LIB cathode materials, as shown in Table 1 (Hu et al., 2013; Zaghib et al., 2013; Islam and Fisher, 2014; Rousse and Tarascon, 2014). The working voltage of Li$\mathrm{S}$ systems is mainly at $2.3-2.1 \mathrm{~V}$ and not as high as commercial cathodes of LIBs. However, this shortcoming is alleviated by the high-specific capacity, resulting in an energy density over five times greater than commercialized metal oxide cathode materials. Moreover, the abundance, low cost, and environmental benignity of sulfur make it an especially attractive material for use in next generation Li-based batteries (Zhang, 2013; Scheers et al., 2014).

Currently, a number of issues have hindered the realization of high-energy Li-S batteries (Bresser et al., 2013). These issues include the inherent insulating nature of sulfur and discharge products, as well as the dissolution of polysulfide species, leading to a low utilization of sulfur in electrochemical reaction. During the discharge-charge process, dissolved high-ordered polysulfides diffuse through the separator and chemically react with Li foil, forming low-ordered polysulfides (Yang et al., 2013a). The reversed process occurs simultaneously as low-ordered polysulfide migrating back to the cathode, called "shuttle effect." These side reactions give rise to serious consumption of active sulfur material and corrosion of anodic Li metal, leading to poor cycle life. Furthermore, the sulfur-based cathode material undergoes an over $80 \%$ of volume expansion during lithiating process, resulting in increased safety concerns (Yang et al., 2013a).

To achieve the practical use of $\mathrm{Li}-\mathrm{S}$ batteries, carbon materials are seen as prevailing strategies in alleviating the issues mentioned above. Since Ji et al. (2009) reported highly ordered mesoporous carbon for Li-S batteries, various carbon materials have been employed in Li-S systems, including zero-dimensional mesoporous particles (Wang et al., 2012, 2014b), one-dimensional nanotubes and nanofibers (Hagen et al., 2012; Liang et al., 2012), two dimensional graphene (Wang et al., 2013b; Gao et al., 2014), and carbon paper (Su and Manthiram, 2012a; Chung and Manthiram, 2014). High conductivity, large pore volume, and desirable pore size of carbon materials are favorable to aid in improving the conductivity of sulfur cathodes while retaining an elevated amount of active sulfur material. Besides, it is widely accepted that the 
sorption effect and specific morphology of carbon nanomaterials effectively retain polysulfides in carbon matrix and support to relieve the deleterious "shuttle effect."

\section{NITROGEN-DOPED CARBONS (N-CARBON) IN SULFUR CATHODE}

Nitrogen-doped carbon materials have extensively applied in energy storage devices including fuel cells (Geng et al., 2012; Cheng et al., 2014), LIBs (Li et al., 2012a; Chang et al., 2013), Li-air batteries (Li et al., 2012b, 2013), as well as many others fields (Lee et al., 2009; Xue et al., 2012). Their various applications in these fields are because of the metal free catalysis effect, high conductivity, distinct morphology, and specific surface properties. Two main synthetic routes are utilized for the production of nitrogen-doped carbon materials (Nishihara and Kyotani, 2012; Zheng et al., 2012). One method employed for the in situ inclusion of nitrogen into the carbon matrix is the use of a nitrogen containing precursor during pyrolysis (Meier et al., 2008; Sharifi et al., 2012; Shin et al., 2012). This method is predominantly used in the fabrication of highly ordered structures such as nitrogen-doped carbon nanotubes and nanofibers. Another strategy for the inclusion of nitrogen heteroatom is the use of a post-treatment method where nitrogen containing agents react with carbon materials to create various nitrogen-doping types, including pyridinic, pyrrolic, and graphitic nitrogen (Hao et al., 2010; Geng et al., 2011; Fellinger et al., 2012). Typically, this approach is generally conducted with ammonia gas under elevated temperature or with ammonium hydroxide in solvothermal process. The use of nitrogen-doped carbons in Li-S batteries can be categorized in three groups, including zero-dimensional porous carbons, one-dimensional CNTs and carbon nanofibers (CNFs), and two dimensional graphene.

\section{NITROGEN-DOPED MESO- AND MICROPOROUS CARBON}

Meso- and microporous carbon materials (MPCs) are widely used in Li-S systems. Nitrogen-doped MPCs (N-MPCs) are predominately prepared by the post-treatment methods. Compared with pristine MPCs, N-MPCs have enhanced conductivity due to the electron configuration of $\mathrm{N}$ atoms. Furthermore, N-MPCs have the additional advantages of high-surface area and large pore volume. These properties make N-MPCs ideal candidates as carbon hosts for sulfur cathodes. Research into the use of nitrogen-doped MPCs for Li-S systems was firstly reported in 2012, which proposed that N-MPCs may improve the conductivity of sulfur, resulting in high-sulfur utilization during $\mathrm{Li}-\mathrm{S}$ cycling process (Sun et al., 2012). This study reported the use of nitrogen-doped mesoporous carbon (NC) as a host for sulfur cathodes. Compared with bare carbon-sulfur composite, NC/S composite showed a higher initial discharge capacity over $1400 \mathrm{~mA} \mathrm{~h} \mathrm{~g}^{-1}$, indicating enhanced sulfur utilization. Furthermore, NC/S is demonstrated lower sulfur cathodic potential, higher redox current density in the $\mathrm{CV}$ profile, and smaller surface charge transfer resistance in EIS test. These results are strong indications of improved electrochemical activity of sulfur because of the inclusion of nitrogen.

More recent research has concentrated on the exploration of the nitrogen effects and different reaction mechanisms in Li-S systems. Sun et al. (2013a) reported the use of nitrogen-enriched mesoporous carbon with tunable nitrogen content as host materials for sulfur cathodes. The nitrogen-doped carbon/sulfur composites delivered a reversible discharge capacity of $758 \mathrm{~mA} \mathrm{~h} \mathrm{~g}^{-1}$ at $0.2 \mathrm{C}$ and $620 \mathrm{~mA} \mathrm{~h}^{-1}$ at $1 \mathrm{C}$ over 100 cycles. The authors proposed that nitrogen-doping facilitates the surface adsorption of polysulfide into mesoporous carbon, thus, preventing polysulfide dissolution. Another research has further determined the catalytic effect of nitrogen-doped carbon and demonstrated an economic strategy toward synthesizing sulfur/carbon composites via a bottom-up catalytic approach (Sun et al., 2013b). As shown in Figure 2, nitrogen-enriched mesoporous carbon acts as a catalyst and oxidizes $\mathrm{H}_{2} \mathrm{~S}$ down to elemental sulfur, allowing sulfur directly formed onto the carbon framework to produce a C/S composite. The authors stated that nitrogen inclusion increases the surface interaction between polysulfides and carbon framework, resulting in the improved performance. The composites exhibited a reversible capacity of $939 \mathrm{~mA} \mathrm{~h} \mathrm{~g}^{-1}$ after 100 cycles at $0.2 \mathrm{C}$ and a rate capability of $527 \mathrm{~mA} \mathrm{~h} \mathrm{~g}^{-1}$ at $5 \mathrm{C}$ after 70 cycles. These two reports clearly identify that nitrogen-doped carbon hosts can improve both capability and stability of Li-S batteries because of enhanced adsorption of polysulfides. However, there is still a lack
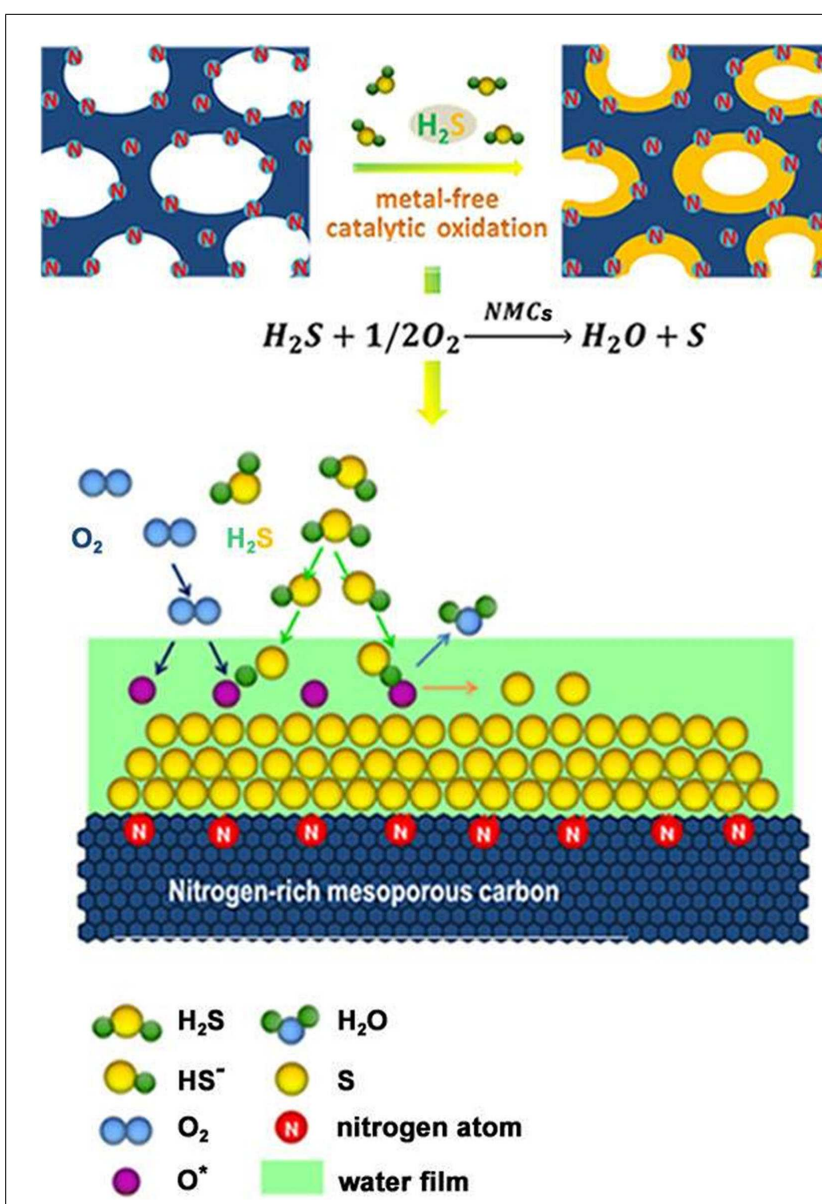

FIGURE 2 | Schematic diagram of the formation of elemental sulfur on the surface of nitrogen-enriched mesoporous carbon (Sun et al., 2013b). 
of understanding behind the exact mechanism that exists between doped nitrogen species and polysulfide species.

Except of "adsorption effect," recent research has confirmed the presence of chemical interactions between N-doped carbon and sulfur-based species. Song et al. (2014) reported the interaction between nitrogen, oxygen, and sulfur in sulfur cathodes. With the use of X-ray absorption near edge structure spectroscopy (Figure 3), the authors determined that nitrogen-doping enable more sulfur accessible to oxygen functional groups on carbon, which is considered as a key role in sulfur immobilization. Recent research conducted by Li et al. (2014a) also demonstrated the presence of chemical interactions between discharge products of lithium sulfides and $\mathrm{N}$ atoms from mesoporous carbon host by synchrotron-based X-ray photoelectron spectroscopy (XPS). The favorable interaction results in a uniform distribution of discharge products and drastically improves the electrochemical performance (Figure 4).

\section{ONE-DIMENSIONAL NITROGEN-DOPED CARBON NANOTUBES AND NANOFIBERS}

One-dimensional multi-walled carbon nanotubes (MWCNTs) and CNFs have been investigated as conductive additives in $\mathrm{Li}-\mathrm{S}$ systems (Su and Manthiram, 2012b). The one-dimensional structure of MWCNTs and CNFs has been confirmed to effectively encapsulate sulfur and prevent polysulfides dissolution (Zheng et al., 2011; Moon et al., 2013). As a result, nitrogen-doped CNTs or CNFs recently have attracted greater attention. Owing to the highly ordered structure of CNTs and CNFs, the most common method for nitrogen inclusion is the use of in situ nitrogen-doping approach (Lee et al., 2011; O’Byrne et al., 2011; Lepró et al., 2012).

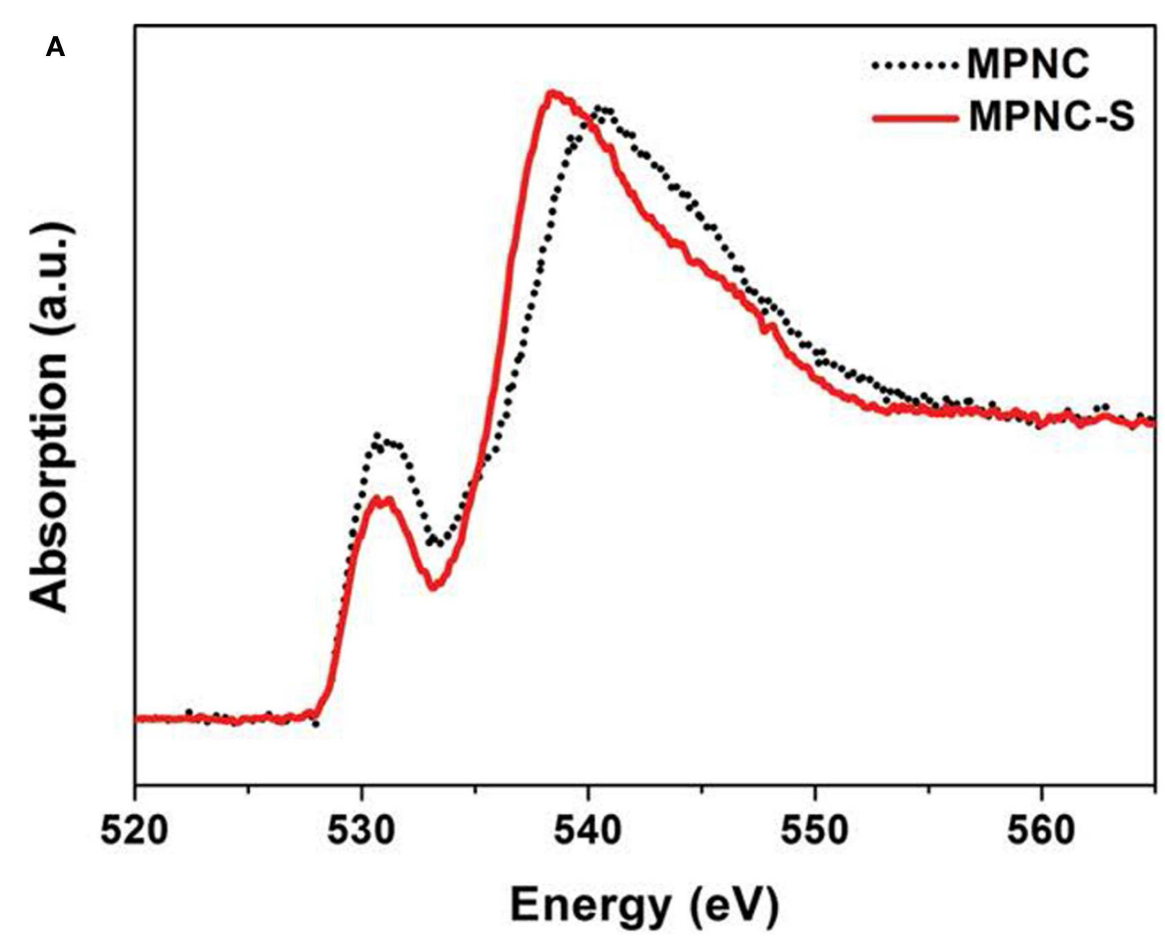

B
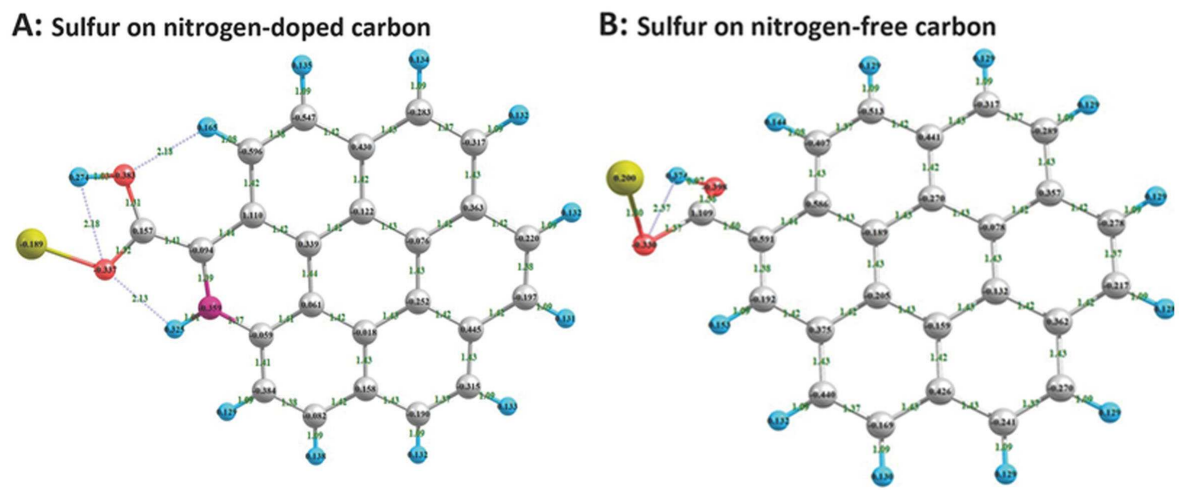

FIGURE 3 | (A) Oxygen K-edge XANES spectra and (B) molecule simulation of mesoporous nitrogen-doped carbon (MPNC) and MPNC-sulfur nanocomposites (Song et al., 2014). 


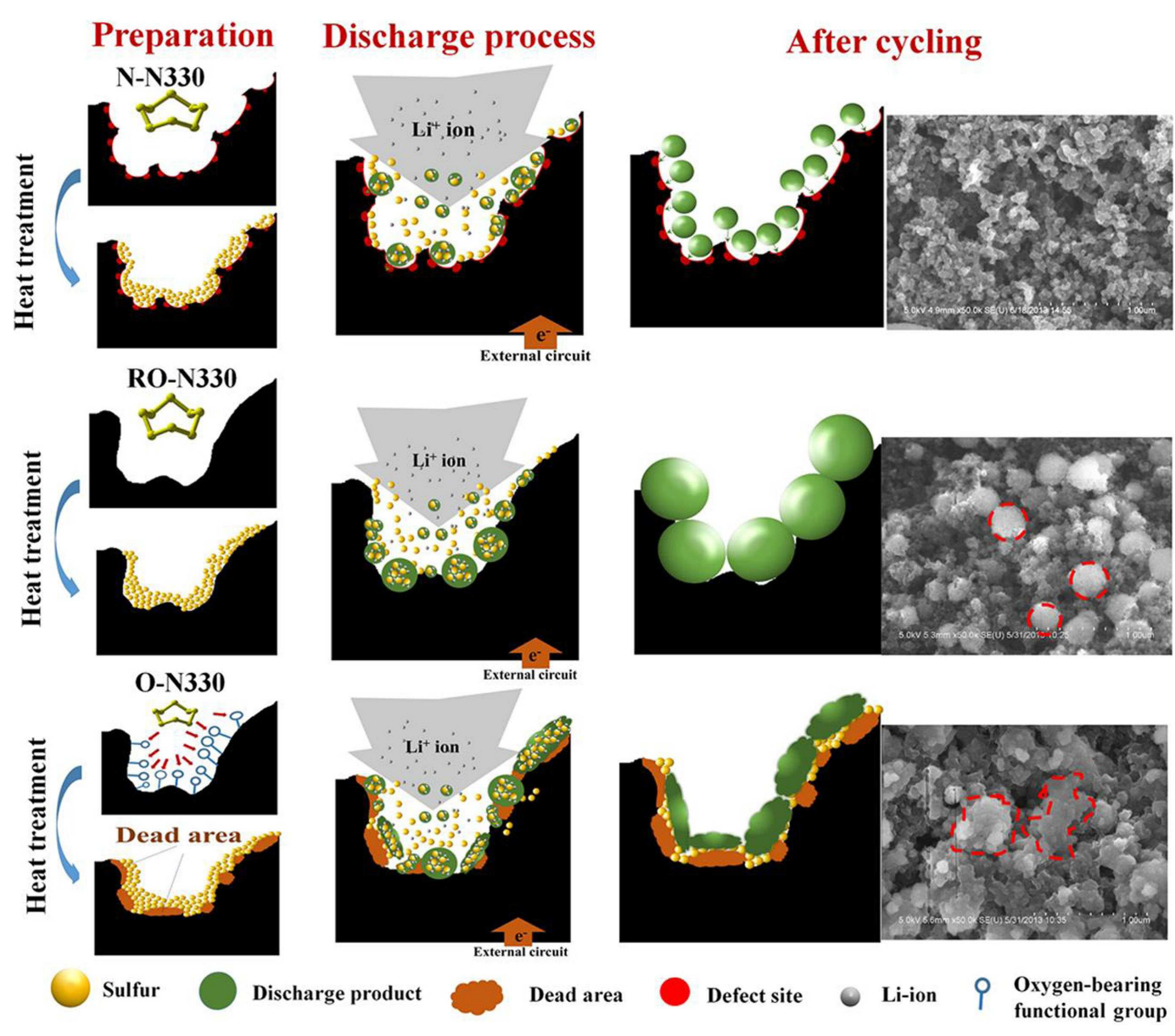

FIGURE 4 | Proposed mechanisms of sulfur-carbon blacks in synthesis and electrochemical reaction (Li et al., 2014a).

The synthetic strategy relies on two steps: (1) growing N-CNTs or N-CNFs with $\mathrm{C}$ and $\mathrm{N}$ containing precursor; and (2) creating porous $\mathrm{N}-\mathrm{CNT}$ or N-CNFs through carbon activation processes. $\mathrm{Xu}$ et al. (2013) reported the use of tubular polypyrrole (TPPY) derived porous nitrogen-doped carbon nanotubes (PNCNTs) in Li-S batteries. The authors proposed that the hierarchical nanoporous structure of PNCNTs facilitates the fast transmission of electrolyte ions. Their results for S/PNCNTs demonstrated a high-initial discharge capacity of over $1341 \mathrm{mAh} \mathrm{g}^{-1}$ and a reversible capacity of $933 \mathrm{mAhg}^{-1}$ under $1 \mathrm{C}$ after 50 cycles. Another study by Li et al. (2014b) reported a similar configuration of nitrogen-doped porous CNTs derived from MWCNTs and pyrrole (MWCNT@S/NPC). Furthermore, the as-prepared sulfur composites were coated with a conductive polymer layer of polyethylene glycol (PEG) to form coaxial structured MWCNTs@S/NPC@PEG nanocable (Figure 5). The authors claimed that the nitrogen-doped porous carbon provided adequate space to encapsulate active sulfur material while the inner MWCNTs and the outer PEG layer maintained fast electron transport and prevented polysulfide dissolution.

Nitrogen-doped carbon nanofibers (N-CNFs) have also been investigated as a host material in sulfur cathodes with similar configuration to N-CNTs. Yang et al. (2014) reported functionalized nitrogen-doped porous carbon nanofiber/sulfur (N-PCNF/S) composites as sulfur cathode materials. The NPCNF/S composites had a high-sulfur load (77.01 wt $\%$ ) and delivered a stabilized discharge capacity of $749.8 \mathrm{~mA} \mathrm{~h}^{-1}$ after 180 cycles at $0.2 \mathrm{C}$. The one-dimensional nitrogen-doped carbon materials featured high $\mathrm{N}$ content and excellent conductivity. However, owing to the in situ nitrogen-doping synthetic process, these papers rarely provide adequate comparison between nitrogen-doped CNTs/CNFs and bare CNTs/CNFs. Furthermore, the exact effect of nitrogen on the electrochemical performance in these systems still remains unclear.

\section{TWO DIMENSIONAL NITROGEN-DOPED GRAPHENE}

Two dimensional graphene has been extensively applied to $\mathrm{Li}-\mathrm{S}$ systems because of their high-surface area, featured morphology, and extraordinary conductivity. Graphene has been exploited as sulfur cathodes in two ways. One is infiltrating sulfur into layer-structured graphene to build a sandwich structured composite (Ji et al., 2011; Kim et al., 2014). The other is by wrapping graphene around sulfur to construct a sulfur-graphene composite (Wang et al., 2011; Evers and Nazar, 2012). However, 
research of nitrogen-doped graphene in sulfur cathodes is very limited. Wang et al. (2014a) reported the use of a porous threedimensional nitrogen-doped graphene (3D-NG) for sulfur cathodes. The nitrogen-doping process was conducted via solvothermal process with ammonium hydroxide as a nitrogen-doping agent (shown in Figure 6). The 3D-NG-sulfur composite (3DNG/S) had a high-sulfur loading content of $87.6 \mathrm{wt} \%$ and exhibited a specific discharge capacity of $792 \mathrm{~mA} \mathrm{~h} \mathrm{~g}^{-1}$ after 145 cycles under $600 \mathrm{~mA} \mathrm{~g}^{-1}$. The authors proposed that $\mathrm{N}$-doping graphene facilitates fast Li-ion transmission and simultaneously traps polysulfide. Moreover, 3D structured graphene can accommodate volume expansion while allowing electrolyte penetration. Compared with other carbon materials, the layer-structured graphene and $\mathrm{N}$-doped graphene have their specific 2D morphology, electronic, and ionic conductivity, considering as new superstars in carbon materials. Application based on nitrogen-doped graphene

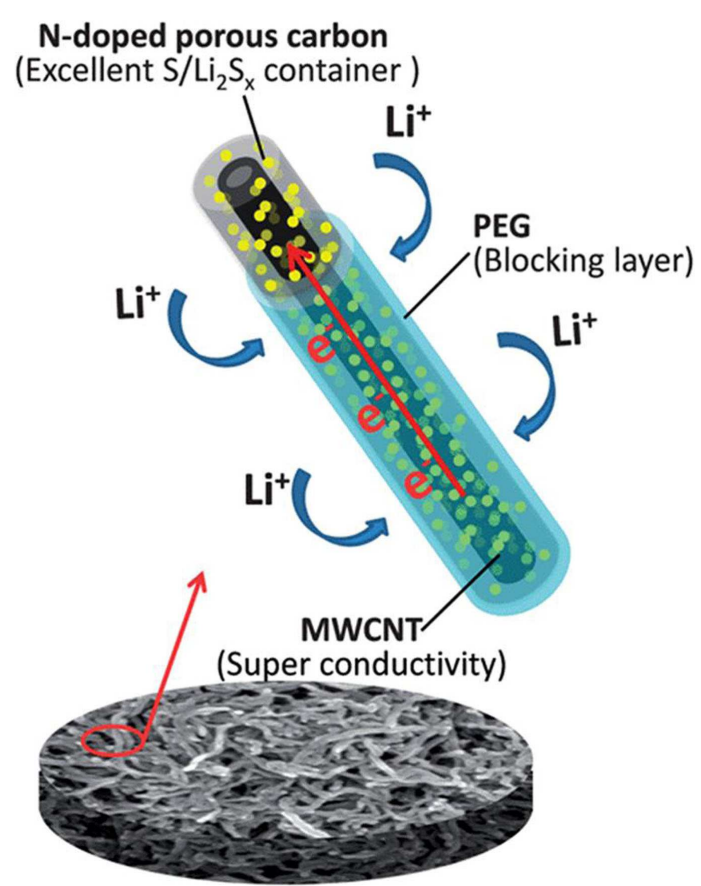

FIGURE 5 | Schematic configuration of MWCNT@S/NPC@PEG (Li et al., 2014b). in Li-S systems is still insufficient and further detailed research is necessary.

\section{NITROGEN-DOPED CARBON IN LITHIUM SULFIDE CATHODES}

Recently, lithium sulfide $\left(\mathrm{Li}_{2} \mathrm{~S}\right)$ has gained attention as a promising cathode material because of its potential to avoid the use of Li metal and the unsafe formation of lithium dendrite (Seh et al., 2013). Furthermore, $\mathrm{Li}_{2} \mathrm{~S}$ cathodes can avoid volume expansion issues because they are already in a fully lithiated state. Besides, $\mathrm{Li}_{2} \mathrm{~S}$ also has an ultrahigh theoretical capacity of $1166 \mathrm{~mA} \mathrm{~h} \mathrm{~g}^{-1}$ (Yang et al., 2012, 2013b). However, research of $\mathrm{Li}_{2} \mathrm{~S}$ is still in its infancy due to many critical issues that currently exist. The nonconductive nature of $\mathrm{Li}_{2} \mathrm{~S}$ and dissolution of intermediate product polysulfides plague the use of $\mathrm{Li}_{2} \mathrm{~S}$, similar to sulfur cathodes, leading to poor cycle life and reduced coulombic efficiency (Han et al., 2014). Especially of the dissolved polysulfides, they will chemically react with cathode and anode parts, called "shuttle effect." Another perilous issue impeding the use of $\mathrm{Li}_{2} \mathrm{~S}$ is its high sensitivity to water and oxygen (Jeong et al., 2013). These issues cause considerable challenges for the application of $\mathrm{Li}_{2} \mathrm{~S}$, requiring elaborated protection of $\mathrm{Li}_{2} \mathrm{~S}$ in order to avoid contact with ambient environment from synthesis to battery assembly (Lin et al., 2013; Seh et al., 2014).

To overcome these issues, carbon materials have been employed for use in the development of $\mathrm{Li}_{2} \mathrm{~S}$ cathodes. These materials include graphene, polymers, as well as mesoporous carbon. Nitrogen heteroatom inclusion in carbon matrix is favorable to the encapsulation of $\mathrm{Li}_{2} \mathrm{~S}$ and allows the carbon material to cover the surface of $\mathrm{Li}_{2} \mathrm{~S}$. Guo et al. (2013) introduced a mechanism outlining the interaction of $\mathrm{Li}$-ions and nitrile groups from polyacrylonitrile (PAN). The authors suggested that this interaction can be exploited to build carbon- $\mathrm{Li}_{2} \mathrm{~S}$ composites and fabricate a uniform distribution of $\mathrm{Li}_{2} \mathrm{~S}$ on carbon, leading to an improved cycle performance. Research conducted by Seh et al. (2014) further confirmed the mechanism of interaction between Li-ions and nitrogen groups. The $\mathrm{Li}_{2} \mathrm{~S}$-polypyrrole composite was synthesized via an in situ polymerization process. Using high-resolution XPS, it was determined the interaction between $\mathrm{N}$ atom from polypyrrole and $\mathrm{Li}$-ion from $\mathrm{Li}_{2} \mathrm{~S}$, which enables polypyrrole to cover the surface of $\mathrm{Li}_{2} \mathrm{~S}$ particle tightly (Figure 7 ). This uniform coating layer can prevent polysulfides dissolution during cycling. Furthermore, the conductive polypyrrole coating enables fast electron transmission, ultimately leading to elevated utilization of $\mathrm{Li}_{2} \mathrm{~S}$.
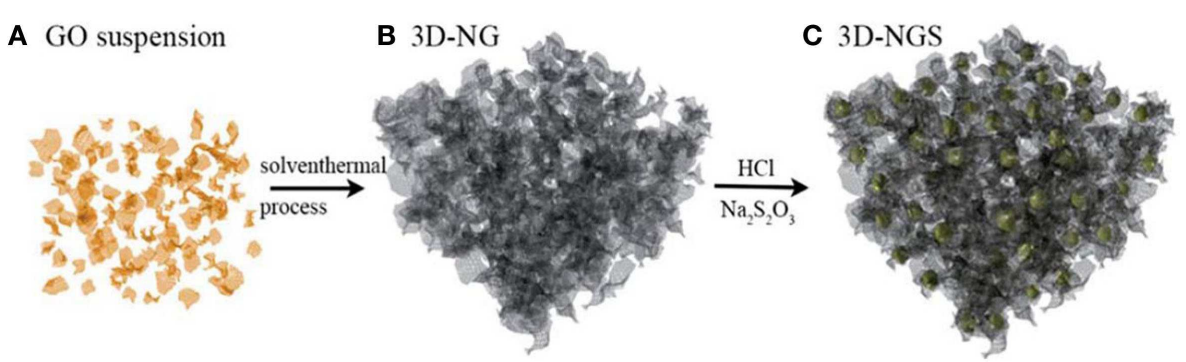

FIGURE 6 | Synthetic step of 3D-nitrogen doped graphene-sulfur composite (3D-NGS) (Wang et al., 2014a) 


\section{SUMMARY AND OUTLOOK}

Li-S batteries are considered as promising high-energy storage devices for the application of long-distance EVs. Two key challenges currently facing the realization of $\mathrm{Li}-\mathrm{S}$ batteries are the improvement of cathode conductivity and the dissolution of polysulfides. The use of carbon as a host material is clearly an excellent strategy toward these issues. This review highlighted a new family of carbon materials, nitrogen-doped carbon, and its application in sulfur and sulfide cathodes, including the use of zero-dimensional mesoporous carbon, one-dimensional carbon nanotubes and nanofibers, and two dimensional graphene. Nitrogen-doped carbon materials are well suited for this application because of their high conductivity, featured morphology, and modified surface properties. The review presented here on nitrogen-doped carbon demonstrates the improved electrochemical performance of these materials and provides a detailed discussion on mechanisms through which nitrogen significantly improves these systems, as

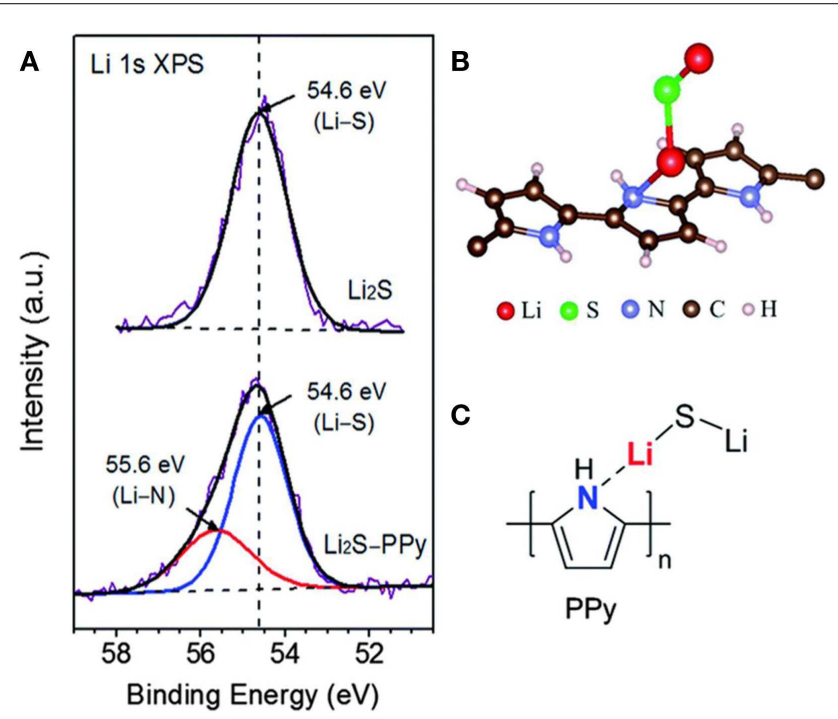

FIGURE 7 | (A) High-resolution Li 1S XPS spectra of bare $\mathrm{Li}_{2} \mathrm{~S}$ and $\mathrm{Li}_{2} \mathrm{~S}-\mathrm{PPy}$ composites, $(\mathbf{B}, \mathbf{C})$ molecule simulation of stable bond between $\mathrm{Li}_{2} \mathrm{~S}$ and PPy (Seh et al., 2014). shown in Table 2. The previous researches have demonstrated clear evidences of the presence of chemical interactions between $\mathrm{N}$-doped carbon and sulfur or sulfide cathodes, enhancing the immobility of polysulfides.

The use of nitrogen-doped carbon for sulfur cathodes has undergone tremendous development, but further improvements in this field need to be established. Understanding of nitrogendoping effects in $\mathrm{Li}-\mathrm{S}$ systems should be further studied. Two main effects of $\mathrm{N}$-doped carbon have been proposed in literature. One is the improved conductivity of $\mathrm{N}$-doped carbon, leading to high utilization of sulfur. The other is the immobility of polysulfides, resulting in stable cycle life. However, not enough work has been done to address the mechanisms governing these phenomena. Detailed research on the correlations between the nitrogen-doping and sulfur cathode performance remains a challenge. Advanced characterization methods, such as synchrotron radiation analysis, can reveal the mechanisms behind the electrochemical performance. Synchrotron-based X-ray spectroscopy is a very powerful tool that can be used to understand the chemical structure of composites in $\mathrm{Li}-\mathrm{S}$ systems. It has been confirmed by synchrotron radiation analysis: (1) the presence of interactions between graphene and sulfur via XAS spectroscopy (Ji et al., 2011); (2) the polysulfides transformation via operando XAS (Cuisinier et al., 2013); and (3) the dissolution effect of polysulfides via operando $\mathrm{X}$-ray diffraction (soft X-ray) and transmission X-ray microscopy (hard X-ray) (Nelson et al., 2012). The research of synchrotron radiation on $\mathrm{N}$-doped or other heteroatom-doped carbon in $\mathrm{Li}-\mathrm{S}$ batteries will shed light on the doping effect on electrochemical performance.

Furthermore, developing high quality and economic N-doped carbon materials is another challenge for applicable Li-S energy storage systems in future: (i) developing methods to synthesize mass-production of N-doped CNTs with low cost; (ii) identifying $\mathrm{N}$ doping types (pyridinic, pyrrolic, and graphitic nitrogen) on which is favorable for battery performance and developing approaches to control the percentages of desirable $\mathrm{N}$ doping type; (iii) understanding surface properties of $\mathrm{N}$-doped carbon and finding ways to reduce the irreversible capacity loss of batteries, resulting from doping effect (Xiao et al., 2013); (iv) improving other heteroatom-doped carbon materials for Li-S, LIBs, and other energy storage systems.

Table 2 | Summary of nitrogen-doped carbons in Li-S system in terms of synthetic method, sulfur load, and electrochemical performance.

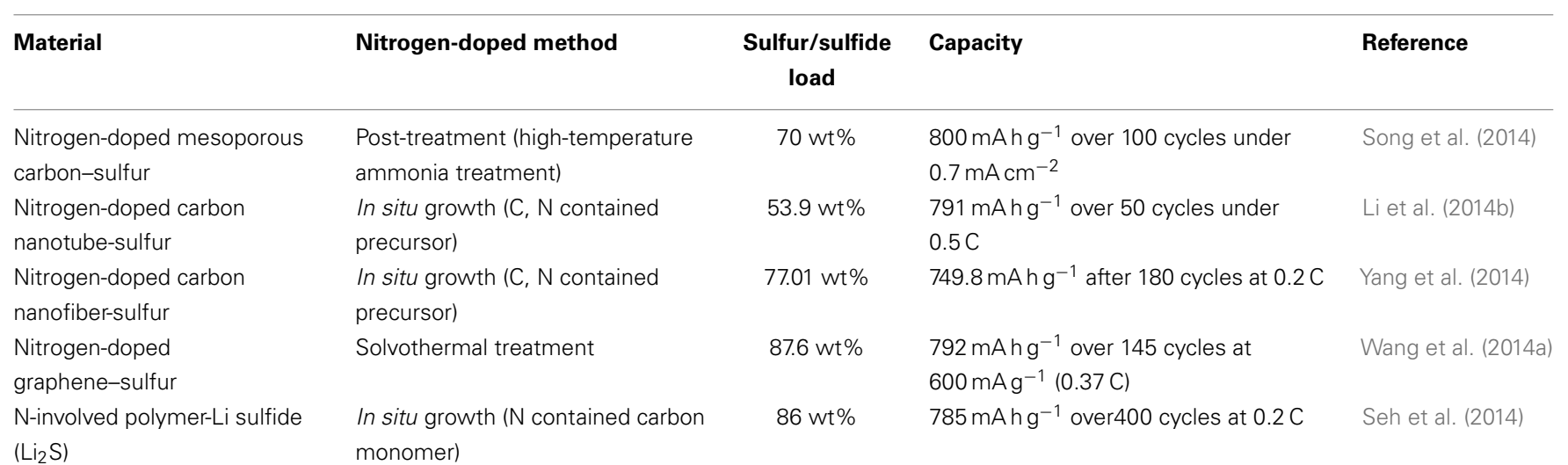




\section{ACKNOWLEDGMENTS}

This research was supported by the Natural Science and Engineering Research Council of Canada (NSERC), Canada Research Chair (CRC) Program, Canadian Foundation for Innovation (CFI), and the University of Western Ontario.

\section{REFERENCES}

Armstrong, M. J., O’Dwyer, C., Macklin, W. J., and Holmes, J. D. (2013). Evaluating the performance of nanostructured materials as lithium-ion battery electrodes. Nano Res. 7, 1-62. doi:10.1007/s12274-013-0375-x

Bresser, D., Passerini, S., and Scrosati, B. (2013). Recent progress and remaining challenges in sulfur-based lithium secondary batteries - a review. Chem. Commun. (Camb) 49, 10545-10562. doi:10.1039/c3cc46131a

Bruce, P. G., Freunberger, S. A., Hardwick, L. J., and Tarascon, J. M. (2012). Li-O2 and Li-S batteries with high energy storage. Nat. Mater. 11, 19-29. doi:10.1038/nmat3191

Chang, K., Geng, D., Li, X., Yang, J., Tang, Y., Cai, M., et al. (2013). Ultrathin MoS2/nitrogen-doped graphene nanosheets with highly reversible lithium storage. Adv. Energy Mater. 3, 839-844. doi:10.1002/aenm.201201108

Cheng, N., Liu, J., Banis, M. N., Geng, D., Li, R., Ye, S., et al. (2014). High stability and activity of Pt electrocatalyst on atomic layer deposited metal oxide/nitrogendoped graphene hybrid support. Int. J. Hydrogen Energy 39, 15967-15974. doi:10.1016/j.ijhydene.2014.01.202

Chung, S. H., and Manthiram, A. (2014). A hierarchical carbonized paper with controllable thickness as a modulable interlayer system for high performance Li-S batteries. Chem. Commun. (Camb) 50, 4184-4187. doi:10.1039/c4cc00850b

Cuisinier, M., Cabelguen, P.-E., Evers, S., He, G., Kolbeck, M., Garsuch, A., et al. (2013). Sulfur speciation in Li-S batteries determined by operando X-ray absorption spectroscopy. J. Phys. Chem. Lett. 4, 3227-3232. doi:10.1002/cphc. 201300972

Dunn, B., Kamath, H., and Tarascon, J. M. (2011). Electrical energy storage for the grid: a battery of choices. Science 334, 928-935. doi:10.1126/science.1212741

Evers, S., and Nazar, L. F. (2012). Graphene-enveloped sulfur in a one pot reaction: a cathode with good coulombic efficiency and high practical sulfur content. Chem. Commun. (Camb) 48, 1233-1235. doi:10.1039/c2cc16726c

Evers, S., and Nazar, L. F. (2013). New approaches for high energy density lithiumsulfur battery cathodes. Acc. Chem. Res. 46, 1135-1143. doi:10.1021/ar3001348

Fellinger, T. P., Hasche, F., Strasser, P., and Antonietti, M. (2012). Mesoporous nitrogen-doped carbon for the electrocatalytic synthesis of hydrogen peroxide. J. Am. Chem. Soc. 134, 4072-4075. doi:10.1021/ja300038p

Gao, X., Li, J., Guan, D., and Yuan, C. (2014). A scalable graphene sulfur composite synthesis for rechargeable lithium batteries with good capacity and excellent columbic efficiency. ACS Appl. Mater. Interfaces 6, 4154-4159. doi:10.1021/ am4057979

Gao, X.-P., and Yang, H.-X. (2010). Multi-electron reaction materials for high energy density batteries. Energy Environ. Sci. 3, 174. doi:10.1039/b916098a

Geng, D., Hu, Y., Li, Y., Li, R., and Sun, X. (2012). One-pot solvothermal synthesis of doped graphene with the designed nitrogen type used as a Pt support for fuel cells. Electrochem. commun. 22, 65-68. doi:10.1016/j.elecom.2012.05.033

Geng, D., Yang, S., Zhang, Y., Yang, J., Liu, J., Li, R., et al. (2011). Nitrogen doping effects on the structure of graphene. Appl. Surf. Sci. 257, 9193-9198. doi:10.1016/j.apsusc.2011.05.131

Goodenough, J. B., and Kim, Y. (2011). Challenges for rechargeable batteries. J. Power Sources 196, 6688-6694. doi:10.1016/j.jpowsour.2010.11.074

Guo, J., Yang, Z., Yu, Y., Abruna, H. D., and Archer, L. A. (2013). Lithium-sulfur battery cathode enabled by lithium-nitrile interaction. J. Am. Chem. Soc. 135, 763-767. doi:10.1021/ja309435f

Hagen, M., Dörfler, S., Althues, H., Tübke, J., Hoffmann, M. J., Kaskel, S., et al. (2012). Lithium-sulphur batteries - binder free carbon nanotubes electrode examined with various electrolytes. J. Power Sources 213, 239-248. doi:10.1016/j.jpowsour. 2012.04.004

Han, K., Shen, J., Hayner, C. M., Ye, H., Kung, M. C., and Kung, H. H. (2014). Li2S-reduced graphene oxide nanocomposites as cathode material for lithium sulfur batteries. J. Power Sources 251, 331-337. doi:10.1016/j.jpowsour.2013.11. 062

Hao, G. P., Li, W. C., Qian, D., and Lu, A. H. (2010). Rapid synthesis of nitrogendoped porous carbon monolith for CO2 capture. Adv. Mater. 22, 853-857. doi:10.1002/adma.200903765
Hu, M., Pang, X., and Zhou, Z. (2013). Recent progress in high-voltage lithium ion batteries. J. Power Sources 237, 229-242. doi:10.1002/cphc.201402175

Islam, M. S., and Fisher, C. A. (2014). Lithium and sodium battery cathode materials: computational insights into voltage, diffusion and nanostructural properties. Chem. Soc. Rev. 43, 185-204. doi:10.1039/c3cs60199d

Jeong, S., Bresser, D., Buchholz, D., Winter, M., and Passerini, S. (2013). Carbon coated lithium sulfide particles for lithium battery cathodes. J. Power Sources 235, 220-225. doi:10.1016/j.jpowsour.2013.01.084

Ji, L., Rao, M., Zheng, H., Zhang, L., Li, Y., Duan, W., et al. (2011). Graphene oxide as a sulfur immobilizer in high performance lithium/sulfur cells. J. Am. Chem. Soc. 133, 18522-18525. doi:10.1021/ja206955k

Ji, X., Lee, K. T., and Nazar, L. F. (2009). A highly ordered nanostructured carbon-sulphur cathode for lithium-sulphur batteries. Nat. Mater. 8, 500-506. doi:10.1038/nmat2460

Kim, K. H., Jun, Y.-S., Gerbec, J. A., See, K. A., Stucky, G. D., and Jung, H.-T. (2014). Sulfur infiltrated mesoporous graphene-silica composite as a polysulfide retaining cathode material for lithium-sulfur batteries. Carbon N. Y. 69, 543-551. doi:10.1016/j.carbon.2013.12.065

Lee, D. H., Lee, J. A., Lee, W. J., and Kim, S. O. (2011). Flexible field emission of nitrogen-doped carbon nanotubes/reduced graphene hybrid films. Small 7, 95-100. doi:10.1002/smll.201001168

Lee, K. T., Jeong, S., and Cho, J. (2013). Roles of surface chemistry on safety and electrochemistry in lithium ion batteries. Acc. Chem. Res. 46, 1161-1170. doi:10.1021/ar200224h

Lee, S. U., Belosludov, R. V., Mizuseki, H., and Kawazoe, Y. (2009). Designing nanogadgetry for nanoelectronic devices with nitrogen-doped capped carbon nanotubes. Small 5, 1769-1775. doi:10.1002/smll.200801938

Lepró, X., Ovalle-Robles, R., Lima, M. D., Elías, A. L., Terrones, M., and Baughman, R. H. (2012). Catalytic twist-spun yarns of nitrogen-doped carbon nanotubes. Adv. Funct. Mater. 22, 1069-1075. doi:10.1002/adfm.201102114

Li, X., Li, X., Banis, M. N., Wang, B., Lushington, A., Cui, X., et al. (2014a). Tailoring interactions of carbon and sulfur in Li-S battery cathode: significant effects of carbon-heteroatom bonds. J. Mater. Chem. A 2, 12866-12872. doi:10.1039/c4ta02007c

Li, Z., Yuan, L., Yi, Z., Liu, Y., Xin, Y., Zhang, Z., et al. (2014b). A dual coaxial nanocable sulfur composite for high-rate lithium-sulfur batteries. Nanoscale 6 , 1653-1660. doi:10.1039/c3nr04347a

Li, X., Liu, J., Zhang, Y., Li, Y., Liu, H., Meng, X., et al. (2012a). High concentration nitrogen doped carbon nanotube anodes with superior $\mathrm{Li}+$ storage performance for lithium rechargeable battery application. J. Power Sources 197, 238-245. doi:10.1016/j.jpowsour.2011.09.024

Li, Y., Wang, J., Li, X., Geng, D., Banis, M. N., Li, R., et al. (2012b). Nitrogen-doped graphene nanosheets as cathode materials with excellent electrocatalytic activity for high capacity lithium-oxygen batteries. Electrochem. Commun. 18, 12-15. doi:10.1016/j.elecom.2012.01.023

Li, Y., Yadegari, H., Li, X., Banis, M. N., Li, R., and Sun, X. (2013). Superior catalytic activity of nitrogen-doped graphene cathodes for high energy capacity sodium-air batteries. Chem. Commun. (Camb) 49, 11731-11733. doi:10.1039/ c3cc46606j

Liang, X., Wen, Z., Liu, Y., Zhang, H., Jin, J., Wu, M., et al. (2012). A composite of sulfur and polypyrrole-multi walled carbon combinatorial nanotube as cathode for Li/S battery. J. Power Sources 206, 409-413. doi:10.1016/j.jpowsour. 2012.01.123

Lin, Z., Liu, Z., Fu, W., Dudney, N. J., and Liang, C. (2013). Phosphorous pentasulfide as a novel additive for high-performance lithium-sulfur batteries. Adv. Funct. Mater. 23, 1064-1069. doi:10.1002/adfm.201370038

Manthiram, A., Fu, Y., and Su, Y. S. (2013). Challenges and prospects of lithiumsulfur batteries. Acc. Chem. Res. 46, 1125-1134. doi:10.1021/ar300179v

Meier, M. S., Andrews, R., Jacques, D., Cassity, K. B., and Qian, D. (2008). Tearing open nitrogen-doped multiwalled carbon nanotubes. J. Mater. Chem. 18, 4143. doi:10.1039/b809348b

Moon, S., Jung, Y. H., Jung, W. K., Jung, D. S., Choi, J. W., and Do, K. (2013). Encapsulated monoclinic sulfur for stable cycling of li-s rechargeable batteries. Adv Mater. 25, 6547-6553. doi:10.1002/adma.201303166

Nelson, J., Misra, S., Yang, Y., Jackson, A., Liu, Y., Wang, H., et al. (2012). In operando $\mathrm{X}$-ray diffraction and transmission $\mathrm{X}$-ray microscopy of lithium sulfur batteries. J. Am. Chem. Soc. 134, 6337-6343. doi:10.1021/ja2121926

Nishihara, H., and Kyotani, T. (2012). Templated nanocarbons for energy storage. Adv. Mater. 24, 4473-4498. doi:10.1002/adma.201201715 
O’Byrne, J. P., Li, Z., Jones, S. L., Fleming, P. G., Larsson, J. A., Morris, M. A., et al. (2011). Nitrogen-doped carbon nanotubes: growth, mechanism and structure. Chemphyschem 12, 2995-3001. doi:10.1002/cphc.201100454

Rousse, G., and Tarascon, J. M. (2014). Sulfate-based polyanionic compounds for li-ion batteries: synthesis, crystal chemistry, and electrochemistry aspects. Chem. Mater. 26, 394-406. doi:10.1021/cm4022358

Scheers, J., Fantini, S., and Johansson, P. (2014). A review of electrolytes for lithiumsulphur batteries. J. Power Sources 255, 204-218. doi:10.1016/j.jpowsour.2014. 01.023

Seh, Z. W., Wang, H., Hsu, P.-C., Zhang, Q., Li, W., Zheng, G., et al. (2014). Facile synthesis of Li2S-polypyrrole composite structures for high-performance Li2S cathodes. Energy Environ. Sci. 7, 672. doi:10.1039/c3ee43395a

Seh, Z. W., Zhang, Q., Li, W., Zheng, G., Yao, H., and Cui, Y. (2013). Stable cycling of lithium sulfide cathodes through strong affinity with a bifunctional binder. Chem. Sci. 4, 3673. doi:10.1039/c3sc51476e

Sharifi, T., Nitze, F., Barzegar, H. R., Tai, C.-W., Mazurkiewicz, M., Malolepszy, A., et al. (2012). Nitrogen doped multi walled carbon nanotubes produced by CVDcorrelating XPS and Raman spectroscopy for the study of nitrogen inclusion. Carbon N. Y. 50, 3535-3541. doi:10.1016/j.carbon.2012.03.022

Shin, W. H., Jeong, H. M., Kim, B. G., Kang, J. K., and Choi, J. W. (2012). Nitrogendoped multiwall carbon nanotubes for lithium storage with extremely high capacity. Nano Lett. 12, 2283-2288. doi:10.1021/nl3000908

Song, J., Xu, T., Gordin, M. L., Zhu, P., Lv, D., Jiang, Y.-B., et al. (2014). Nitrogendoped mesoporous carbon promoted chemical adsorption of sulfur and fabrication of high-areal-capacity sulfur cathode with exceptional cycling stability for lithium-sulfur batteries. Adv. Funct. Mater. 24, 1243-1250. doi:10.1002/adfm. 201302631

Song, M. K., Cairns, E. J., and Zhang, Y. (2013). Lithium/sulfur batteries with high specific energy: old challenges and new opportunities. Nanoscale 5, 2186-2204. doi:10.1039/c2nr33044j

Su, Y. S., and Manthiram, A. (2012a). Lithium-sulphur batteries with a microporous carbon paper as a bifunctional interlayer. Nat. Commun. 3, 1166. doi:10.1038/ncomms2163

Su, Y. S., and Manthiram, A. (2012b). A new approach to improve cycle performance of rechargeable lithium-sulfur batteries by inserting a free-standing MWCNT interlayer. Chem. Commun. (Camb) 48, 8817-8819. doi:10.1039/ c2cc33945e

Sun, F., Wang, J., Chen, H., Li, W., Qiao, W., Long, D., et al. (2013a). High efficiency immobilization of sulfur on nitrogen-enriched mesoporous carbons for Li-S batteries. ACS Appl. Mater. Interfaces 5, 5630-5638. doi:10.1021/ am400958x

Sun, F., Wang, J., Chen, H., Qiao, W., Ling, L., and Long, D. (2013b). Bottom-up catalytic approach towards nitrogen-enriched mesoporous carbons/sulfur composites for superior Li-S cathodes. Sci. Rep. 3, 2823. doi:10.1038/ srep02823

Sun, X. G., Wang, X., Mayes, R. T., and Dai, S. (2012). Lithium-sulfur batteries based on nitrogen-doped carbon and an ionic-liquid electrolyte. ChemSusChem 5, 2079-2085. doi:10.1002/cssc.201200101

Wang, C., Su, K., Wan, W., Guo, H., Zhou, H., Chen, J., et al. (2014a). High sulfur loading composite wrapped by $3 \mathrm{D}$ nitrogen-doped graphene as a cathode material for lithium-sulfur batteries. J. Mater. Chem. A 2, 5018. doi:10.1039/ c3ta14921h

Wang, W. G., Wang, X., Tian, L. Y., Wang, Y. L., and Ye, S. H. (2014b). In situ sulfur deposition route to obtain sulfur-carbon composite cathodes for lithium-sulfur batteries. J. Mater. Chem. A 2, 4316. doi:10.1039/c3ta14459c

Wang, D., Zeng, Q., Zhou, G., Yin, L., Li, F., Cheng, H., et al. (2013). Carbonsulfur composites for Li-S batteries: status and prospects. J. Mater. Chem. A 1, 9382-9394. doi:10.1039/c3ta11045a

Wang, D. W., Zhou, G., Li, F., Wu, K. H., Lu, G. Q., Cheng, H. M., et al. (2012). A microporous-mesoporous carbon with graphitic structure for a high-rate stable sulfur cathode in carbonate solvent-based Li-S batteries. Phys. Chem. Chem. Phys. 14, 8703-8710. doi:10.1039/c2cp40808b

Wang, H., Yang, Y., Liang, Y., Robinson, J. T., Li, Y., Jackson, A., et al. (2011). Graphene-wrapped sulfur particles as a rechargeable lithium-sulfur battery cathode material with high capacity and cycling stability. Nano Lett. 11, 2644-2647. doi: $10.1021 / \mathrm{nl} 200658 \mathrm{a}$
Wang, J., Li, Y., and Sun, X. (2013a). Challenges and opportunities of nanostructured materials for aprotic rechargeable lithium-air batteries. Nano Energy 2, 443-467. doi:10.1016/j.nanoen.2012.11.014

Wang, L., Wang, D., Zhang, F., and Jin, J. (2013b). Interface chemistry guided longcycle-life Li-S battery. Nano Lett. 13, 4206-4211. doi:10.1021/nl4018868

Xiao, B., Li, X., Li, X., Wang, B., Langford, C., Li, R., et al. (2013). Graphene nanoribbons derived from the unzipping of carbon nanotubes: controlled synthesis and superior lithium storage performance. J. Phys. Chem. C 118, 881-890. doi:10.1021/jp410812v

Xu, G., Ding, B., Nie, P., Shen, L., Wang, J., and Zhang, X. (2013). Porous nitrogendoped carbon nanotubes derived from tubular polypyrrole for energy-storage applications. Chemistry 19, 12306-12312. doi:10.1002/chem.201301352

Xu, W., Wang, J., Ding, F., Chen, X., Nasybulin, E., Zhang, Y., et al. (2014). Lithium metal anodes for rechargeable batteries. Energy Environ. Sci. 7, 513. doi:10.1039/c3ee40795k

Xue, Y., Liu, J., Chen, H., Wang, R., Li, D., Qu, J., et al. (2012). Nitrogen-doped graphene foams as metal-free counter electrodes in high-performance dyesensitized solar cells. Angew. Chem. Int. Ed. Engl. 51, 12124-12127. doi:10.1002/ anie. 201207277

Yang, J., Xie, J., Zhou, X., Zou, Y., Tang, J., Wang, S., et al. (2014). Functionalized N-doped porous carbon nanofiber webs for a lithium-sulfur battery with high capacity and rate performance. J. Phys. Chem. C 118, 1800-1807. doi:10.1021/jp410385s

Yang, Y., Zheng, G., and Cui, Y. (2013a). Nanostructured sulfur cathodes. Chem. Soc. Rev. 42, 3018-3032. doi:10.1039/c2cs35256g

Yang, Z., Guo, J., Das, S. K., Yu, Y., Zhou, Z., Abruña, H. D., et al. (2013b). In situ synthesis of lithium sulfide-carbon composites as cathode materials for rechargeable lithium batteries. J. Mater. Chem. A 1, 1433. doi:10.1039/c2ta00779g

Yang, Y., Zheng, G., Misra, S., Nelson, J., Toney, M. F., and Cui, Y. (2012). Highcapacity micrometer-sized Li2S particles as cathode materials for advanced rechargeable lithium-ion batteries. J. Am. Chem. Soc. 134, 15387-15394. doi: 10.1021/ja3052206

Yin, Y. X., Xin, S., Guo, Y. G., and Wan, L. J. (2013). Lithium-sulfur batteries: electrochemistry, materials, and prospects. Angew. Chem. Int. Ed. Engl. 52, 13186-13200. doi:10.1002/anie.201304762

Zaghib, K., Guerfi, A., Hovington, P., Vijh, A., Trudeau, M., Mauger, A., et al. (2013). Review and analysis of nanostructured olivine-based lithium recheargeable batteries: status and trends. J. Power Sources 232, 357-369. doi:10.1016/j.jpowsour. 2012.12.095

Zhang, S. S. (2013). Sulfurized carbon: a class of cathode materials for high performance lithium/sulfur batteries. Front. Energy Res. 1:10. doi:10.3389/fenrg.2013. 00010

Zheng, G., Yang, Y., Cha, J. J., Hong, S. S., and Cui, Y. (2011). Hollow carbon nanofiber-encapsulated sulfur cathodes for high specific capacity rechargeable lithium batteries. Nano Lett. 11, 4462-4467. doi:10.1021/nl2027684

Zheng, Y., Jiao, Y., Jaroniec, M., Jin, Y., and Qiao, S. Z. (2012). Nanostructured metal-free electrochemical catalysts for highly efficient oxygen reduction. Small 8, 3550-3566. doi:10.1002/smll.201200861

Conflict of Interest Statement: The authors declare that the research was conducted in the absence of any commercial or financial relationships that could be construed as a potential conflict of interest.

Received: 29 August 2014; paper pending published: 25 September 2014; accepted: 18 October 2014; published online: 04 November 2014.

Citation: Li X and Sun X (2014) Nitrogen-doped carbons in Li-S batteries: materials design and electrochemical mechanism. Front. Energy Res. 2:49. doi: 10.3389/fenrg.2014.00049

This article was submitted to Energy Storage, a section of the journal Frontiers in Energy Research.

Copyright (C) $2014 \mathrm{Li}$ and Sun. This is an open-access article distributed under the terms of the Creative Commons Attribution License (CC BY). The use, distribution or reproduction in other forums is permitted, provided the original author(s) or licensor are credited and that the original publication in this journal is cited, in accordance with accepted academic practice. No use, distribution or reproduction is permitted which does not comply with these terms. 